\title{
A More Precise Computation of Along Wind Dynamic Response Analysis for Tall Buildings Built in Urban Areas
}

\author{
Shu-Xun Chen \\ Guangxi University, Nanning, Guangxi, China \\ E-mail:chenshx@gxu.edu.cn \\ Received November 12, 2009; revised January 25, 2010; accepted February 4, 2010
}

\begin{abstract}
Modern tall buildings are generally built in urban areas, where value of the terrain roughness length is much greater than that of the general terrain areas, therefore wind-induced vibrations become more pronounced. The present formulas of numerical analysis of wind-induced response become less accurate. A more accurate expression of along-wind load spectrum matrix is proposed. On the basis of the expression, structural analysis formula of along-wind displacement and acceleration response are developed and programmed. The rationality of these formulas are illustrated in examples.
\end{abstract}

Keywords: Tall Building, Wind Load Spectrum, Wind-Induced Vibration, Response Analysis, Structural Analysis

\section{Introduction}

In modern cities, buildings get taller and more slender. The effects of wind-induced motions become more pronounced. Accurate prediction of structural response to wind-induced random vibrations displacement and vibration acceleration at the design stage is a basis for structural safety design and serviceability design of modern tall buildings. The wind-induced response consists of along-wind response, across-wind response and torsion response [1,2]. The paper focuses on along-wind response analysis firstly.

Several quasi-static methods in wind codes in various countries and approximate methods based on wind tunnel studies are used to predict the wind-induced response. As a building gets taller, the wind-induced random vibrations becomes more violent, these methods become less reliable. So the wind-induced response of modern tall buildings should be assessed accurately by using the theory of random vibration. Using the numerical analysis methods of random vibration response of tall buildings, people calculate structural response according to wind load spectra. According to present literatures [2-5] whose representative is literature [3], considering that the values of terrain roughness lengths are generally very small, and the turbulence densities are also very small, square items of the turbulence component are neglected in expression

The project supported by Dr Chun-Man Chan of HKUST. formula of the wind load in along-wind direction. But, for the modern tall buildings built in urban areas, the values of terrain roughness lengths are much more than ones for general buildings in general open areas. So that these items should not be neglected for tall buildings, as they are the same order values with some items that are not neglected. Otherwise, calculation results of the turbulence response of the tall buildings will have a large relative error.

To overcome the above-mentioned error, a more accurate expression of wind load spectrum matrixes is proposed in this paper. This expression is especially applicable to tall and other important buildings. Even an approximate form of the accurate expression is more precise than the present expression [3]. On the basis of this expression of wind load spectrum, structural analysis formulas of wind-induced displacement response and acceleration response in along-wind direction are developed and programmed. The expression forms of wind load spectrum and the analysis formulas proposed in this paper are especially suitable for using the models of the structural finite element analysis of tall buildings and their results of vibration modal analysis. These analysis results of wind-induced response can be directly used in member stress analysis, structural deformation analysis and structural serviceability analysis of tall buildings.

Rationality of the expression forms of wind load spectrum and the analysis formulas proposed is shown in comparison examples. 


\section{Expression of Wind Load Spectrum Matrix}

\subsection{Wind-Induced Load Vector}

Wind around tall building flows in a complex and random way, so the wind is a random process. Wind loads acting on windward walls are mainly caused by the steady flow and the turbulence flow. The wind speed at node $i$ of the windward walls can be expressed as:

$$
V_{i}(t)=V_{0 i}+V_{r i}(t)
$$

where $V_{0 i}$ is the mean wind speed at node $i, V_{0 i}$ can be obtained with the following formulas:

$$
V_{0 i}=V_{0}\left(h_{i} / h_{0}\right)^{\alpha}
$$

here $V_{0}$ is standard wind speed at a reference height $h_{0}$, e.g. $10 \mathrm{~m}, \alpha=0.12 \sim 0.30, h_{i}$ is height of node $i . V_{r i}(t)$ in Equation (1) is the fluctuate wind speed at height $h_{i}$, its power spectrum density $S_{r i}(\omega)$ can be determined by fomulas of the present representative literature [3].

Because along-wind drag force is directly proportional to the square of relative wind speed, wind load acting vertically on node $i$ of windward walls of a tall building can be expressed as:

$$
\begin{aligned}
P_{u i} & =c_{i} a_{i}(\rho / 2)\left[V_{i}(t)-U_{i}{ }^{\prime}\right]^{2} \\
& =c_{i} a_{i}(\rho / 2)\left[V_{i}(t)^{2}-2 V_{i}(t) U_{i}{ }^{\prime}+U_{i}{ }^{\prime 2}\right]
\end{aligned}
$$

in which

$c_{i}$----- $c_{i}$ is the drag coefficient describing the ratio of the wind load per unit area at $i$ node and the velocity pressure $(\rho / 2)\left[V_{i}(t)-U_{i}{ }^{\prime}\right]^{2}$.

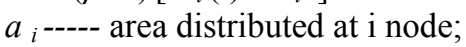

$\rho$----- air density

$U_{i}{ }^{\prime}$----- along-wind displacement speed of node $i$.

In Equation (3), since wind speed $V_{i}(t)$ is much greater than the structural displacement speed $U_{i}{ }^{\prime}$, the high order small value $U_{i}{ }^{\prime 2}$ can be undoubtedly neglected, then we can get

$$
P_{u i}(t)=c_{i} a_{i}(\rho / 2)\left[V_{i}(t)^{2}-2 V_{i}(t) U_{i}^{\prime}\right]
$$

Let

$$
C_{a i}=c_{i} a_{i}(\rho / 2) 2 V_{i}(t) \approx c_{i} a_{i} \rho V_{0 i}
$$

Adding $C_{a i}$ to the structural damping coefficient $C_{s i}$, a total damping coefficient $C_{i}$ is obtained :

$$
C_{i}=C_{s i}+C_{a i}
$$

It is taken as the $\mathrm{i}$-th diagonal element of damping matrix $\boldsymbol{C}$ of the structural dynamic equation of the tall building shown in Equation (7):

$$
\boldsymbol{K} \boldsymbol{U}+\boldsymbol{C} \boldsymbol{U}^{\prime}+\boldsymbol{M} \boldsymbol{U}^{\prime}=\boldsymbol{P}(t)
$$

Then the along-wind load vector of the tall building can be expressed as:

$$
\begin{aligned}
\boldsymbol{P}_{\boldsymbol{u}}(t)= & \left\{c_{i} a_{i}(\rho / 2) V_{i}(t)^{2}\right\} \\
& (i=1,2, \ldots, N)
\end{aligned}
$$

where $N$ is the total number of structural freedom degrees. In Equation (8), if $i$ does not correspond to the along-wind load of the nodes of the windward walls, then $c_{i}$ is taken as zero.

Place Equation (1) into Equation (8) :

$$
\begin{aligned}
\boldsymbol{P}_{\boldsymbol{u}}(t)= & \left\{c_{i} a_{i}(\rho / 2)\left[V_{0 i}+V_{r i}(t)\right]^{2}\right\} \\
= & \left\{c_{i} a_{i}(\rho / 2)\left[V_{0 i}{ }^{2}+2 V_{0 i} V_{r i}(t)+V_{r i}{ }^{2}(t)\right]\right\} \\
& (i=1,2, \ldots, N)
\end{aligned}
$$

In the present literature, e.g. in page 76 of the present representative literature [3], $V_{r i}{ }^{2}(t)$ is neglected, then

$$
\begin{aligned}
\overline{\boldsymbol{P}}_{u}(t)= & \left\{c_{i} a_{i}(\rho / 2)\left[V_{0 i}{ }^{2}+2 V_{0 i} V_{r i}(t)\right]\right\} \\
& (i=1,2, \ldots, N)
\end{aligned}
$$

The author consider that $V_{r I}^{2}(t)$ should not be neglected for tall buildings in urban areas. The author's reason is as follows:

In Equation (1), $V_{r i}(t)$ is the turbulent flow speed at $i$ node. It is a random process with a zero mean value. Its variance is determined by the following equations:

$$
\sigma_{r i}^{2}\left(h_{i}\right)=E\left[V_{r i}{ }^{2}(t)\right]=V_{o i}{ }^{2} I_{r i}{ }^{2}
$$

where $I_{r i}$ is the turbulence density at $i$ node, it can be obtained from the following equation [3]:

$$
I_{r i}=\sigma_{r i}\left(h_{i}\right) / V_{o i}=1 / \ln \left(h_{i} / r_{0}\right)
$$

where $h_{i}$ is the height of $i$ node, $r_{0}$ is the roughness length of building terrain, $r_{0}=10^{-5} \sim 10$ meter is determined by the terrain type. Because most of the modern tall buildings are usually built in urban areas, roughness length $r_{0}$ of urban area is about 1-10 meter [3], which is a very great value. $V_{r i}{ }^{2}(t)$ is not much less than $V_{0 i}{ }^{2}$, for instance, when $r_{0}=3 \mathrm{~m}$ and $h_{i}=22 \mathrm{~m}$, then $I_{r i}=\sigma_{r i}\left(h_{i}\right) /$ $V_{o i}=0.5$. In Equation (11), $\sigma_{r i}{ }^{2}\left(h_{i}\right)=E\left[V_{r i}{ }^{2}(t)\right]=$ $V_{o i}{ }^{2} I_{r i}{ }^{2}=0.25 V_{o i}{ }^{2}$. When $h_{i}=22 \mathrm{~m}$, the relationship curve of $I_{r i}{ }^{2}$ and $r_{0}$ is showm in Figure 1:

It is shown in the The relationship curve in Figure 1 that $I_{r i}{ }^{2}$ of tall buildings in urban area of is much more

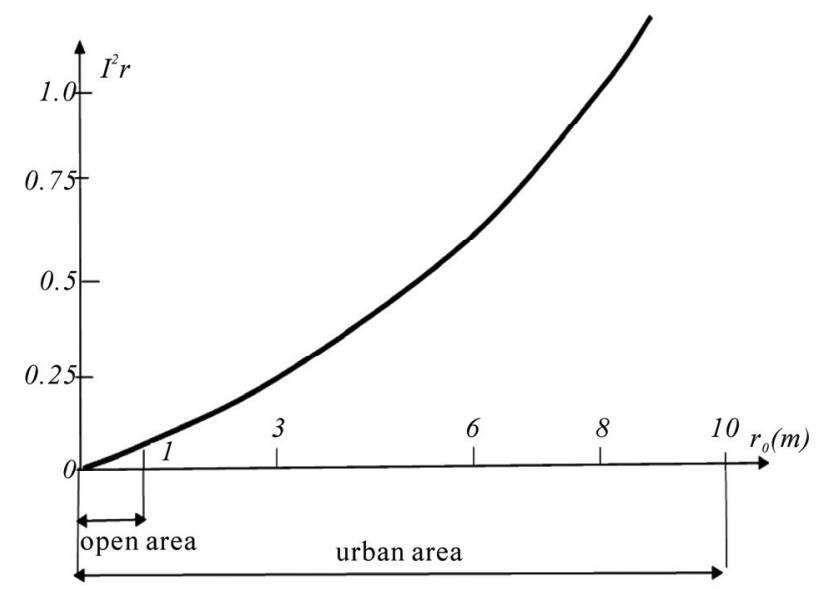

Figure 1. The relationship curve of $I_{r i}{ }^{2}$ and $r_{0}$. 
than one of general buildings in open area. Considering Equation (11), $V_{r i}{ }^{2}(t)$ of Equation (9) can not be neglected, and Equation (10) with $V_{r i}{ }^{2}(t)$ neglected can only be applied to buildings built in general open terrain. For modern tall buildings in urban areas, Equation (10) will cause a large relative error.

\subsection{Wind Load Correlation Matrix}

Correlation matrix of the wind load vector shown as Equation (9) is

$$
\boldsymbol{R}_{\boldsymbol{P} u}(\tau)=E\left[\boldsymbol{P}_{\boldsymbol{u}}(t) \boldsymbol{P}_{\boldsymbol{u}}^{T}(t+\tau)\right]
$$

Its element of row $\mathrm{i}$, column $\mathrm{j}$ is:

$$
\begin{aligned}
\mathrm{R}_{\mathrm{Puij}}(\tau) & =c_{i} c_{j} a_{i} a_{j}(\rho / 2)^{2} E\left\{\left[V_{0 i}+V_{r i}(t)\right]^{2}\right. \\
& \left.\times\left[V_{0 j}+V_{r j}(t+\tau)\right]^{2}\right\} \\
& =c_{i} c_{j} a_{i} a_{j}(\rho / 2)^{2} E\left[V_{o i}{ }^{2} V_{o j}{ }^{2}\right. \\
& +2 V_{o i}{ }^{2} V_{o j} V_{r j}(t+\tau)+2 V_{o i} V_{o j}{ }^{2} V_{r i}(t) \\
& +V_{o i}{ }^{2} V_{r j}{ }^{2}(t+\tau)+V_{o j}{ }^{2} V_{r i}{ }^{2}(t) \\
& +4 V_{o i} V_{o j} V_{r i}(t) V_{r j}(t+\tau) \\
& +2 V_{o i} V_{r i}(t) V_{r j}{ }^{2}(t+\tau)+2 V_{o j} V_{r i}{ }^{2}(t) V_{r j}(t+\tau) \\
& \left.+V_{r i}{ }^{2}(t) V_{r j}{ }^{2}(t+\tau)\right]
\end{aligned}
$$

Because $V_{r i}(t)$ and $V_{r j}(t+\tau)$ are stationary ergodic normal distributive random processes $[2,5,6]$, then

$$
\begin{aligned}
& E\left[V_{r i}(t)\right]=E\left[V_{r j}(t+\tau)\right]=0 \\
& E\left[V_{r i}{ }^{2}(t)\right]=\sigma_{r i}{ }^{2} \\
& E\left[V_{r j}^{2}(t+\tau)\right]=\sigma_{r j}{ }^{2} \\
& E\left[V_{r i}(t) V_{r j}(t+\tau)\right]=R_{r i j}(\tau) \\
& E\left[V_{r i}^{2}(t) V_{r j}(t+\tau)\right]=E\left[V_{r i}(t) V_{r j}^{2}(t+\tau)\right]=0 \\
& E\left[V_{r i}^{2}(t) V_{r j}^{2}(t+\tau)\right]=\sigma_{r i}{ }^{2} \sigma_{r j}{ }^{2}+2 R_{r i j}{ }^{2}(\tau)
\end{aligned}
$$

Then Equation (14) can be:

$$
\begin{aligned}
R_{P u i j}(\tau)= & c_{i} c_{j} a_{i} a_{j}(\rho / 2)^{2}\left[V_{o i}{ }^{2} V_{o j}{ }^{2}\right. \\
& +V_{o i}{ }^{2} \sigma_{r j}{ }^{2}+V_{o j}{ }^{2} \sigma_{r i}{ }^{2}+\sigma_{r i}{ }^{2} \sigma_{r j}{ }^{2} \\
& \left.+4 V_{o i} V_{o j} R_{r i j}(\tau)+2 R_{r i j}{ }^{2}(\tau)\right]
\end{aligned}
$$

Considering Equation (12), the element of row $i$, column $j$ of the correlation matrix of the wind load can be obtained:

$$
\begin{aligned}
R_{P u i j}(\tau) & =c_{i} c_{j} a_{i} a_{j}(\rho / 2)^{2}\left[V_{o i}{ }^{2} V_{o j}{ }^{2}\right. \\
& \times\left(1+I_{r i}{ }^{2}+I_{r j}{ }^{2}+I_{r i}{ }^{2} I_{r j}{ }^{2}\right) \\
& \left.+4 V_{o i} V_{o j} R_{r i j}(\tau)+2 R_{r i j}{ }^{2}(\tau)\right]
\end{aligned}
$$

In the present literature [3], $V_{r i}{ }^{2}(t)$ of wind load is neglected as Equation (10), then the correlation matrix shown in Equation (13) is

$$
\boldsymbol{R}_{\overline{\boldsymbol{P}}_{u}}(\tau)=E\left[\overline{\boldsymbol{P}}_{u}(t) \overline{\boldsymbol{P}}_{u}{ }^{T}(t+\tau)\right]
$$

The element of of row $i$, column $j$ of the correlation matrix of the wind load is

$$
\begin{aligned}
R_{\bar{P} u i j}(\tau) & =c_{i} c_{j} a_{i} a_{j}(\rho / 2)^{2}\left[V_{o i}^{2} V_{o j}^{2}\right. \\
& \left.+4 V_{o i} V_{o j} R_{r i j}(\tau)\right]
\end{aligned}
$$

Comparing Equation (24) and Equation (22), their relative error is a quite large for modern tall buildings built in urban areas.

\subsection{Wind Load Spectrum Matrix}

From Equation (22), a spectrum matrix of the wind load vector can be obtained:

$$
S_{P u}(\omega)=[1 /(2 \pi)] \int_{-\infty}^{\infty} R_{P u}(\tau) e^{-j \omega \tau} d \tau
$$

Its element of row $\mathrm{i}$, column $\mathrm{j}$ is:

$$
S_{P u i j}(\omega)=[1 /(2 \pi)] \int_{-\infty}^{\infty} R_{P u i j}(\tau) e^{-j \omega \tau} d \tau(26)
$$
is:

Placing Equation (22) into Equation (26), the result

$$
\begin{aligned}
& S_{P u i j}(\omega)=c_{i} c_{j} a_{i} a_{j}(\rho / 2)^{2}\left[V_{o i}{ }^{2} V_{o j}{ }^{2}\right. \\
& \quad \times\left(1+I_{r i}{ }^{2}+I_{r j}{ }^{2}+I_{r i}{ }^{2} I_{r j}{ }^{2}\right) \delta(\omega) \\
& \left.\quad+4 V_{o i} V_{o j} S_{r i j}(\omega)+2 S_{r i j}(\omega) * S_{r i j}(\omega)\right]
\end{aligned}
$$

in which the symbol * expresses Duhamel integral, $\delta(\omega)$ is the $\delta$ - function:

$$
\delta(\omega)=[1 /(2 \pi)] \int_{-\infty}^{\infty} e^{-j \omega \tau} d \tau
$$

and

$$
S_{r i j}(\omega)=[1 /(2 \pi)] \int_{-\infty}^{\infty} R_{r i j}(\tau) e^{-j \omega \tau} d \tau
$$

$S_{r i j}(\omega)$ is a cross-spectrum of turbulent wind velocity, which can be obtained from literature $[2,12]$.

A good approximate expression of Equation (27) is

$$
\begin{aligned}
S_{P u i j}(\omega) & =c_{i} c_{j} a_{i} a_{j}(\rho / 2)^{2}\left[V _ { o i } { } ^ { 2 } V _ { o j } { } ^ { 2 } \left(1+I_{r i}{ }^{2}\right.\right. \\
& \left.\left.+I_{r j}{ }^{2}\right) \delta(\omega)+4 V_{o i} V_{o j} S_{r i}(\omega)\right]
\end{aligned}
$$

In the comparison example in this paper, relative error of Equation (30) and Equation (27) will be discussed.

If $V_{r i}{ }^{2}(t)$ of Equation (9) is neglected as Equation (10), then the element of row $i$, column $j$ of the wind load spectrum matrix is:

$$
\begin{gathered}
S_{\bar{P} u i j}(\omega)=c_{i} c_{j} a_{i} a_{j}(\rho / 2)^{2}\left[V_{o i}{ }^{2} V_{o j}{ }^{2} \delta(\omega)+4\right. \\
\left.V_{o i} V_{o j} S_{r i j}(\omega)\right]
\end{gathered}
$$

Comparing with Equation (31), the approximate expression Equation (30) has more items $\left(I_{r I}{ }^{2}+I_{r j}{ }^{2}\right)$, which is the same order value as the item corresponding 
to $4 V_{o i} V_{o j} S_{r i j}(\omega)$, and should not be neglected. Their necessity is shown in the following formulas of wind-induced response analysis.

\section{Wind-Induced Response Analysis}

Wind-induced structural responses in along-wind direction include a static part, i.e. an along-wind translation, and a dynamic part, i.e. an along-wind random vibration. The along-wind translation is mainly caused by the steady flow. The along-wind vibration is caused by the turbulent flow. The along-wind random vibration includes a quasi-steady background turbulence response to low frequency component and a narrow-band resonant response.

\subsection{Displacement Response Analysis}

According to the analysis method of random vibration response, the calculation formula of spectrum matrix of the displacement response vector can be expressed as:

$$
\boldsymbol{S}_{\boldsymbol{u}}(\omega)=\boldsymbol{H}_{\boldsymbol{u}}(\omega) \boldsymbol{S}_{\boldsymbol{P} u}(\omega) \boldsymbol{H}_{\boldsymbol{u}} *(\omega)
$$

in which the spectrum matrix of wind-induced load $\boldsymbol{S}_{\boldsymbol{P} \boldsymbol{u}}(\omega)$ is shown as Equation (25), $\boldsymbol{H}_{\boldsymbol{u}}{ }^{*}(\omega)$ is the conjugate matrixes of frequency response matrix $\boldsymbol{H}_{\boldsymbol{u}}(\omega)$, and

$$
\boldsymbol{H}_{\boldsymbol{u}}(\omega)=\boldsymbol{\phi}_{u} H_{u}(\omega) \boldsymbol{\phi}_{u}{ }^{\boldsymbol{T}}
$$

In which $\phi_{u}$ and $H_{u}(\omega)$ are the natural vibration shape and the frequency response function of the lower along-wind vibration model respectively. The relationship between the vibration shape and mass matrix is $\phi_{u}{ }^{T} \boldsymbol{M} \phi_{u}$ $=M_{u} *=1 . H_{u}(\omega)$ can be obtained from the following formula:

$$
H_{u}(\omega)=1 /\left[\left(\omega_{u}{ }^{2}-\omega^{2}\right)+j 2 \beta_{u} \omega_{u} \omega\right]
$$

in which $\omega_{u}$ and $\beta_{u}$ are the natural frequency and damping of the lowest along-wind vibration model.

The element of row $\mathrm{i}$, column $\mathrm{j}$ of the displacement spectrum matrix shown in Equation (32) is:

$$
S_{u i j}(\omega)=\phi_{i u} \phi_{j u} \sum_{m=1}^{N} \sum_{n=1}^{N} \phi_{m u} \phi_{n u} / H_{u}(\omega) / 2 S_{P u m n}(\omega)
$$

In which $\phi_{i u}$ is the $\mathrm{i}$-th element of vibration shape $\phi_{u}$ of the along-wind vibration mode. $S_{P \text { u m } n}(\omega)$ is shown as Equation (27). $/ H_{u}(\omega) /$ is the absolute value of the frequency response functions of the along-wind vibration mode shown in Equation (34).

According to the response analysis theory of random vibration, the across mean square value matrix of the displacement response is:

$$
E\left[\boldsymbol{U}_{u}^{2}(t)\right]=\boldsymbol{R}_{u}(0)=\int_{-\infty}^{\infty} \boldsymbol{S}_{\boldsymbol{u}}(\omega) d \omega
$$

Its $N$ diagonal elements are mean square values of the displacement response of the $N$ node freedom degrees. They are marked as a vector $\boldsymbol{\psi}_{u}{ }^{2}$. It includes the following two parts:

$$
\psi_{u}{ }^{2}=\mu_{u}{ }^{2}+\sigma_{u}{ }^{2}
$$

its $\mathrm{i}$-th element is the mean square value of displacement response of the $i$-th freedom degree. It is obtained from the following equation:

$$
\begin{aligned}
\psi_{u i}{ }^{2} & =\int_{-\infty}^{\infty} S_{u i i}(\omega) d \omega=\phi_{i u}{ }^{2} \sum_{m=1}^{N} \sum_{n=1}^{N} \phi_{m u} \phi_{n u} \\
& \times \int_{-\infty}^{\infty} / H_{u}(\omega) /{ }^{2} S_{P u m n}(\omega) d \omega
\end{aligned}
$$

in which $S_{P u m n}(\omega)$ is shown as Equation (27).

In Equation (37), $\boldsymbol{\mu}_{\boldsymbol{u}}{ }^{2}$ is the square value vector of the static translation response. Its $i$-th element is the square value of the static translation of the $\mathrm{i}$-th freedom degree. It is

$$
\begin{aligned}
\mu_{u i}{ }^{2} & =\phi_{i u}{ }^{2} \sum_{m=1}^{N} \sum_{n=1}^{N} \phi_{m u} \phi_{n u} c_{m} c_{n} a_{m} a_{n} \\
& \times(\rho / 2)^{2} \quad V_{o m}{ }^{2} V_{o n}{ }^{2} / \omega_{u}{ }^{4}
\end{aligned}
$$

In Equation (37), $\sigma_{u}{ }^{2}$ is the mean square value vector of the dynamic random vibration displacement response. Its $i$-th element is the mean square value of the random vibration displacement of the $\mathrm{i}$-th freedom degree. It is

$$
\begin{aligned}
\sigma_{u i}{ }^{2} & =\phi_{i u}{ }^{2} \sum_{m=1}^{N} \sum_{n=1}^{N} \phi_{m u} \phi_{n u} c_{m} c_{n} a_{m} a_{n}(\rho / 2)^{2} \\
& \times\left\{\left[V_{o m}{ }^{2} V_{o n}{ }^{2}\left(I_{r m}{ }^{2}+I_{r n}{ }^{2}+I_{r m}{ }^{2} I_{r n}{ }^{2}\right)\right] / \omega_{u}{ }^{4}\right. \\
& +\int_{-\infty}^{\infty} / H_{u}(\omega) /^{2}\left[4 V_{o m} V_{o n} S_{r m n}(\omega)\right. \\
& \left.\left.+2 S_{r m n}(\omega) * S_{r m n}(\omega)\right] d \omega\right\}
\end{aligned}
$$

in which $S_{r m n}(\omega)$ is shown as Equation (29).

For convenience of computation, $S_{P u m n}(\omega)$ of Equation (27) can be taken as its approximate form shown in Equation (30). So the mean square value of the random vibration displacement of the $\mathrm{i}$-th freedom degree of the tall building $\sigma_{u i}{ }^{2}$ becomes:

$$
\begin{aligned}
\sigma_{u i}{ }^{2} & =\phi_{i u}{ }^{2} \sum_{m=1}^{N} \sum_{n=1}^{N} \phi_{m u} \phi_{n u} c_{m} c_{n} a_{m} a_{n}(\rho / 2)^{2} \\
& \times\left\{\left[V_{o m}{ }^{2} V_{o n}{ }^{2}\left(I_{r m}{ }^{2}+I_{r n}{ }^{2}\right)\right] / \omega_{u}{ }^{4}\right. \\
& \left.+\int_{-\infty}^{\infty} / H_{u}(\omega) / 24 V_{o m} V_{o n} S_{r m n}(\omega) d \omega\right\}
\end{aligned}
$$


Considering:

$$
\begin{aligned}
& \int_{-\infty}^{\infty} / H_{u}(\omega) / 2 S_{r m n}(\omega) d \omega \approx \int_{-\infty}^{\infty} / H_{u}(0) / 2 \\
& \times S_{r m n}(\omega) d \omega+\int_{\infty_{u}-\Delta \omega}^{\infty_{u}+\Delta \omega} / H_{u}(\omega) /{ }^{2} S_{r m n}(\omega) d \omega \\
& \approx r_{m n} \sigma_{r m} \sigma_{r n} / \omega_{u}{ }^{4}+S_{r m n}\left(\omega_{u}\right)\left[\pi /\left(2 \beta_{u} \omega_{u}{ }^{3}\right)\right]
\end{aligned}
$$

where $/ H_{u}\left(\omega_{u}\right) /^{2}=1 /\left(2 \beta_{u} \omega_{u}{ }^{2}\right)^{2}, \Delta \omega=\pi \beta_{u} \omega_{u} r_{m n}$ is cross correlation. By convention of the present representative literature [3], $\sigma_{u i}{ }^{2}$ of Equation (41) can be divided to the following two parts:

$$
\sigma_{u i}{ }^{2} \approx \sigma_{u b i}{ }^{2}+\sigma_{u r i}{ }^{2}
$$

in which $\sigma_{u b i}{ }^{2}$ is corresponding to the quasi-static turbulent ground displacement response of the i-th freedom degree. It is shown as follows:

$$
\begin{aligned}
\sigma_{u b i}{ }^{2} & =\phi_{i u}{ }^{2} \sum_{m=1}^{N} \sum_{n=1}^{N} \phi_{m u} \phi_{n u} c_{m} c_{n} a_{m} a_{n}(\rho / 2)^{2} \\
& \times V_{o m}{ }^{2} V_{o n}{ }^{2}\left(I_{r m}{ }^{2}+I_{r n}{ }^{2}\right) / \omega_{u}{ }^{4} \\
& +\phi_{i u}{ }^{2} \sum_{m=1}^{N} \sum_{n=1}^{N} \phi_{m u} \phi_{n u} c_{m} c_{n} a_{m} a_{n}(\rho / 2)^{2} \\
& \times 4 V_{o m} V_{o n} \int_{-\infty}^{\infty} / H_{u}(0) /{ }^{2} S_{r m n}(\omega) d \omega \\
& =\phi_{i u}{ }^{2} \sum_{m=1}^{N} \sum_{n=1}^{N} \phi_{m u} \phi_{n u} c_{m} c_{n} a_{m} a_{n}(\rho / 2)^{2} \\
& \times V_{o m}{ }^{2} V_{o n}{ }^{2}\left(I_{r m}{ }^{2}+I_{r n}{ }^{2}+4 r_{m n} I_{r m} I_{r n}\right) / \omega_{u}{ }^{4}
\end{aligned}
$$

In Equation (43), $\sigma \mathrm{u} \mathrm{r}^{2}$ is corresponding to the dynamic turbulent resonant displacement response of the i-th freedom degree. It is shown as:

$$
\begin{aligned}
\sigma_{u r i}^{2} & =\phi_{i u}{ }^{2} \sum_{m=1}^{N} \sum_{n=1}^{N} \phi_{m u} \phi_{n u} c_{m} c_{n} a_{m} a_{n} \rho^{2} \\
& \times V_{o m} V_{o n} \int_{\infty_{u}-\Delta \omega}^{\infty_{u}+\Delta \omega} / H_{u}(\omega) /{ }^{2} S_{r m n}(\omega) d \omega \\
& =\phi_{i u}{ }^{2} \sum_{m=1}^{N} \sum_{n=1}^{N} \phi_{m u} \phi_{n u} c_{m} c_{n} a_{m} a_{n} \rho^{2} V_{o m} V_{o n} \\
& \times S_{r m n}\left(\omega_{u}\right)\left[\pi /\left(2 \beta_{u} \omega_{u}{ }^{3}\right)\right]
\end{aligned}
$$

If the quasi-static turbulent ground displacement response of Equation (44) is calculated according to the unreasonable approximate Equation (31) as the present representative literature [3], then it is

$$
\begin{aligned}
\bar{\sigma}_{u b i}{ }^{2} & =\phi_{i u}{ }^{2} \sum_{m=1}^{N} \sum_{n=1}^{N} \phi_{m u} \phi_{n u} c_{m} c_{n} a_{m} a_{n}(\rho / 2)^{2} \\
& \times 4 V_{o m} V_{o n} \int_{-\infty}^{\infty} / H_{u}(0) /{ }^{2} S_{r m n}(\omega) d \omega \\
& =\phi_{i u}{ }^{2} \sum_{m=1}^{N} \sum_{n=1}^{N} \phi_{m u} \phi_{n u} c_{m} c_{n} a_{m} a_{n}(\rho / 2)^{2} \\
& \times V_{o m}{ }^{2} V_{o n}{ }^{2}\left(4 r_{m n} I_{r m} I_{r n}\right) /\left(\omega_{u}{ }^{4}\right)
\end{aligned}
$$

In Equation (44), Comparing the relative values of the two items $\left(4 r_{m n} I_{r m} I_{r n}\right.$ and $\left.I_{r m}{ }^{2}+I_{r n}{ }^{2}\right)$, it is obvious that the items corresponding to $\left(I_{r i}{ }^{2}+I_{r j}{ }^{2}\right)$ of Equation (30) can not be neglected as Equation (31), since the neglecting will cause a $50 \%$ or much higher relative error for the quasi-static turbulent ground displacement response.

\subsection{Acceleration Response Analysis}

Wind-induced acceleration response of a tall building are random values with zero mean values. Similar to Equation (37)-(40), the mean square value of acceleration response of the i-th freedom degree can be calculated as:

$$
\begin{aligned}
\sigma_{u, i}{ }^{2} & =\phi_{i u}{ }^{2} \sum_{m=1}^{N} \sum_{n=1}^{N} \phi_{m u} \phi_{n u} \int_{-\infty}^{\infty} \omega^{4} \\
& \times / H_{u}(\omega) /{ }^{2} S_{P u m n}(\omega) d \omega \\
& =\phi_{i u}{ }^{2} \sum_{m=1}^{N} \sum_{n=1}^{N} \phi_{m u} \phi_{n u} c_{m} c_{n} a_{m} a_{n}(\rho / 2)^{2} \\
& \times \int_{-\infty}^{\infty} \omega^{4} / H_{u}(\omega) / 2\left\{V _ { o m } { } ^ { 2 } V _ { o n } { } ^ { 2 } \left[1+I_{r m}{ }^{2}\right.\right. \\
& \left.+I_{r n}{ }^{2}+I_{r m}{ }^{2} I_{r n}{ }^{2}\right] \delta(\omega)+4 V_{o m} V_{o n} S_{r m n}(\omega) \\
& \left.+2 S_{r m n}(\omega) * S_{r m n}(\omega)\right\} d \omega
\end{aligned}
$$

Considering $\omega^{4} / H_{u}(\omega) / 2=0$ when $\omega=0$, can get

$$
\begin{aligned}
\sigma_{u, i}^{2} & =\phi_{i u}{ }^{2} \sum_{m=1}^{N} \sum_{n=1}^{N} \phi_{m u} \phi_{n u} c_{m} c_{n} a_{m} a_{n}(\rho / 2)^{2} \\
& \times \int_{-\infty}^{\infty} \omega^{4} / H_{u}(\omega) /^{2}\left[4 V_{o m} V_{o n} S_{r m n}(\omega)\right. \\
& \left.+2 S_{r m n}(\omega) * S_{r m n}(\omega)\right] d \omega
\end{aligned}
$$

Its approximate expression is shown as follows: 


$$
\begin{aligned}
\sigma_{u " i}{ }^{2} & =\phi_{i u}{ }^{2} \sum_{m=1}^{N} \sum_{n=1}^{N} \phi_{m u} \phi_{n u} c_{m} c_{n} a_{m} a_{n} \rho^{2} \\
& \times V_{o m} V_{o n} \int_{-\infty}^{\infty} \omega^{4} / H_{u}(\omega) /{ }^{2} S_{r m n}(\omega) d \omega
\end{aligned}
$$

With reference to Equation (42), it can be calculated as:

$$
\begin{aligned}
\sigma_{u, i}{ }^{2} & \approx \phi_{i u}{ }^{2} \sum_{m=1}^{N} \sum_{n=1}^{N} \phi_{m u} \phi_{n u} c_{m} c_{n} a_{m} a_{n} \rho^{2} \\
& \times V_{o m} V_{o n} S_{r m n}\left(\omega_{1}\right)\left[\pi \omega_{u} /\left(2 \beta_{u}\right)\right]
\end{aligned}
$$

It is now widely accepted that wind-induced acceleration response has become the standard for the serviceability evaluation of motion perception in tall buildings. So Acceleration response analysis of tall buildings is of an important and practical significance

\section{Example}

Structure of a certain tall building is described as a 50 -storey of 7-bay by 10-bay framework with 2550 nodes and 5100 members shown in Figure 2.

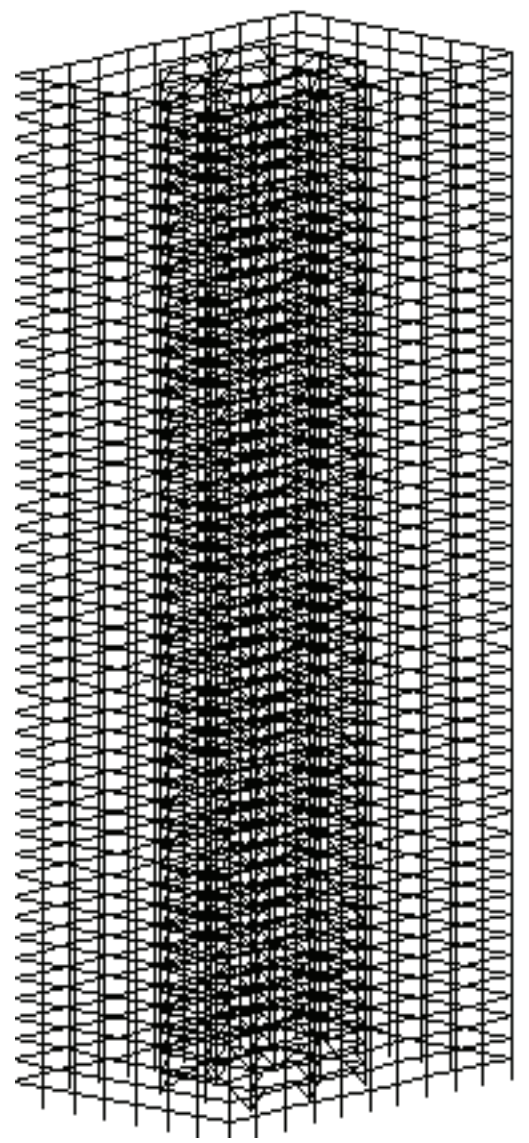

Figure 2. 3D model of the example building
A bay width is $4.57 \mathrm{~m}$ and a storey height is $3.66 \mathrm{~m}$. Details of the framework are shown in its plan view in Figure 3 and elevation views in Figure 4 and 5.

The framework consists of exterior moment frames and a braced core, which are rectangles with the same centre. All beams and columns are rigidly connected while the diagonal braces are simply connected. Two-storey Kbracing modules are used on both the south and north faces of the core, as shown in Figure 4. Single-storey kneebracing is used in the west and east faces of the core as shown in Figure 4.

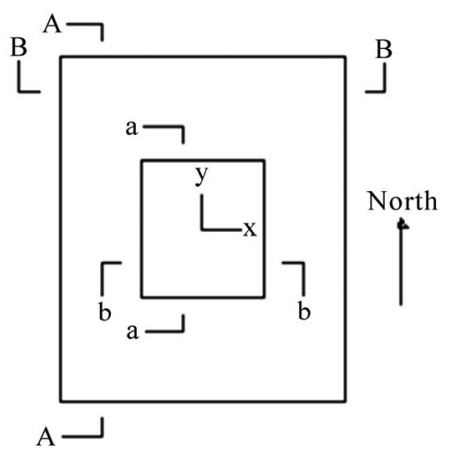

Figure 3. Plan view of the example

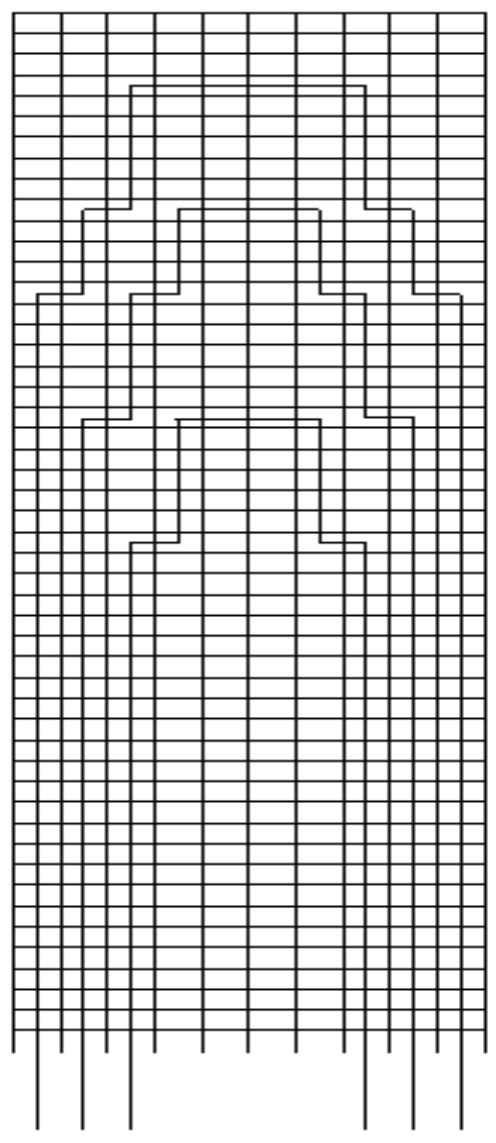

Figure 4. A-A view and drag coefficients $c_{i}$ 

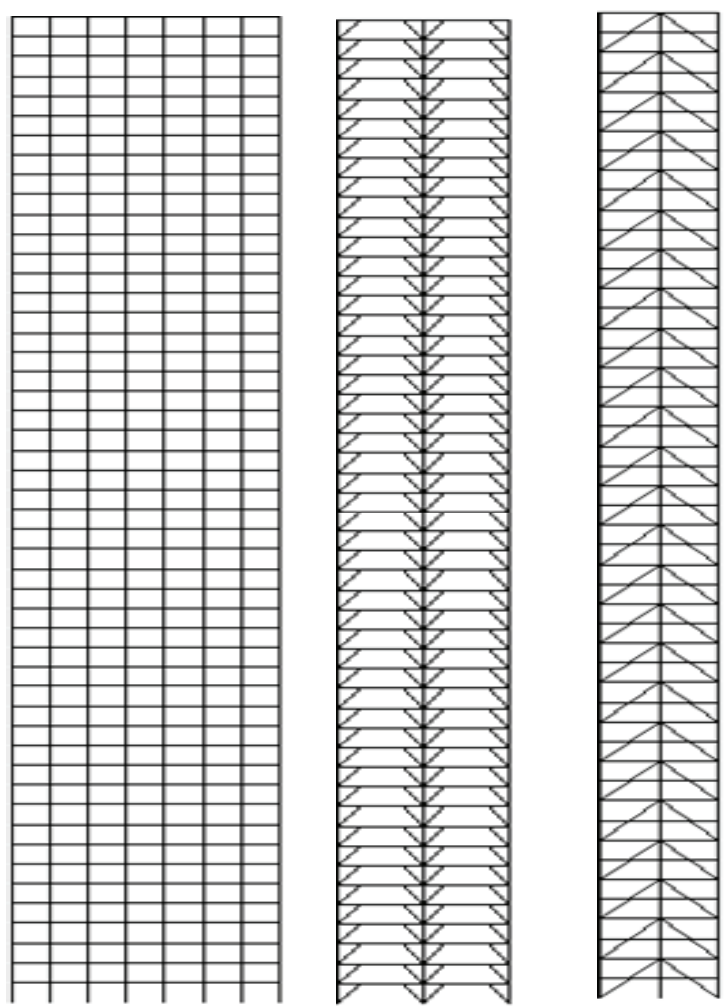

Figure. 5 B-B view Figure 6. a-a view

Figure 7. b-b view

The floors between the exterior frames and braced core are rigid. Mass density of the tall building is $150 \mathrm{~kg} / \mathrm{m}^{3}$, which is employed when node masses of this framework are calculated. American AISC standard sections are used to size the members: Beams are W24 $\times 103$ shapes, diagonals are W14 $\times 90$ shapes, and columns are also W14 $\times 233$ shapes except that the cruciform columns in the core (See Figure 3) use pairs of two W14 $\times 233$ shapes oriented perpendicular to each other.
The parameters about wind load are given as follows: the reference height $h_{0}=10 \mathrm{~m}$, the designed wind speed at the reference height $V_{h 0}=30.0 \mathrm{~m} / \mathrm{s}^{2}$, the roughness length of building terrain $r_{0}=2 \mathrm{~m}$, for Equation (11) and Equation (12), $I_{r i}=\sigma_{r i}\left(h_{i}\right) / V_{o i}>17.4 \%$ at nodes over 22 meters. Non-dimensional decay constants $C_{y}=$ $C_{z}=10.0$ which is employed when cross-spectrums of turbulent wind are calculated, The drag coefficients $c_{i}$ of surface nodes in along-wind direction are shown out as Figure 4.

In Table 1, the first, the second and third frequencies of natural vibration are given out. They are corresponding the bending vibration on X-direction, the bending vibration on Y-direction and the twist vibration of the tall building respectively.

Firstly, through the modal analysis, the lowest frequency and its vibration shape are obtained. They are corresponding to the bending vibration in along-wind direction, i.e. X-direction. Its circular frequency is $\omega_{u}=$ $0.86572 \mathrm{rad} / \mathrm{s}$, its natural frequency is 0.13778 hertz.

In Table 2, the translation values of the bending vibration shapes on X-direction (along-wind direction) are listed. The relationship between the vibration shape and mass matrix are $\phi_{u}{ }^{T} \boldsymbol{M} \phi_{u}=M_{u}{ }^{*}=1$. Because the floors between the exterior frames and braced core are rigid, the translation values at all nodes of the same storey are the same.

Table 1. Natural frequencies

\begin{tabular}{cccc}
\hline $\begin{array}{c}\text { mode } \\
\text { number }\end{array}$ & $\begin{array}{c}\text { circular } \\
\text { frequency }\end{array}$ & $\begin{array}{c}\text { frequency } \\
(\text { hertz })\end{array}$ & $\begin{array}{c}\text { period } \\
(\mathrm{sec})\end{array}$ \\
\hline 1 & $8.6572 \mathrm{E}-01$ & $8.6572 \mathrm{E}-01$ & $7.2577 \mathrm{E}+00$ \\
2 & $9.6824 \mathrm{E}-01$ & $1.5410 \mathrm{E}-01$ & $6.4893 \mathrm{E}+00$ \\
3 & $1.2926 \mathrm{E}+00$ & $2.0573 \mathrm{E}-01$ & $4.8608 \mathrm{E}+00$ \\
\hline
\end{tabular}

Table 2. The bending vibration shapes in along-wind direction

\begin{tabular}{cccccccccc}
\hline Storey & X-translation & Storey & X-translation & Storey & X-translation & Storey & X-translation & Storey & X-translation \\
\hline 1 & $.14613 \mathrm{E}-05$ & 11 & $.44215 \mathrm{E}-04$ & 21 & $.11164 \mathrm{E}-03$ & 31 & $.18569 \mathrm{E}-03$ & 41 & $.25427 \mathrm{E}-03$ \\
2 & $.40615 \mathrm{E}-05$ & 12 & $.50177 \mathrm{E}-04$ & 22 & $.11898 \mathrm{E}-03$ & 32 & $.19293 \mathrm{E}-03$ & 42 & $.26052 \mathrm{E}-03$ \\
3 & $.70606 \mathrm{E}-05$ & 13 & $.56396 \mathrm{E}-04$ & 23 & $.12639 \mathrm{E}-03$ & 33 & $.20013 \mathrm{E}-03$ & 43 & $.26670 \mathrm{E}-03$ \\
4 & $.10390 \mathrm{E}-04$ & 14 & $.62780 \mathrm{E}-04$ & 24 & $.13381 \mathrm{E}-03$ & 34 & $.20722 \mathrm{E}-03$ & 44 & $.27271 \mathrm{E}-03$ \\
5 & $.14206 \mathrm{E}-04$ & 15 & $.69378 \mathrm{E}-04$ & 25 & $.14127 \mathrm{E}-03$ & 35 & $.21426 \mathrm{E}-03$ & 45 & $.27865 \mathrm{E}-03$ \\
6 & $.18365 \mathrm{E}-04$ & 16 & $.76104 \mathrm{E}-04$ & 26 & $.14871 \mathrm{E}-03$ & 36 & $.22117 \mathrm{E}-03$ & 46 & $.28442 \mathrm{E}-03$ \\
7 & $.22932 \mathrm{E}-04$ & 17 & $.83006 \mathrm{E}-04$ & 27 & $.15618 \mathrm{E}-03$ & 37 & $.22803 \mathrm{E}-03$ & 47 & $.29012 \mathrm{E}-03$ \\
8 & $.27790 \mathrm{E}-04$ & 18 & $.90002 \mathrm{E}-04$ & 28 & $.16360 \mathrm{E}-03$ & 38 & $.23473 \mathrm{E}-03$ & 48 & $.29567 \mathrm{E}-03$ \\
9 & $.33000 \mathrm{E}-04$ & 19 & $.97138 \mathrm{E}-04$ & 29 & $.17102 \mathrm{E}-03$ & 39 & $.24137 \mathrm{E}-03$ & 49 & $.30121 \mathrm{E}-03$ \\
10 & $.38456 \mathrm{E}-04$ & 20 & $.10434 \mathrm{E}-03$ & 30 & $.17836 \mathrm{E}-03$ & 40 & $.24786 \mathrm{E}-03$ & 50 & $.30640 \mathrm{E}-03$ \\
\hline
\end{tabular}


Table 3. The wind-induced response in along-wind direction

\begin{tabular}{ccccccc}
\hline Storey & $\mu_{u i}{ }^{2}\left(\mathrm{~m}^{2}\right)$ & $\sigma_{u b i}{ }^{2}\left(\mathrm{~m}^{2}\right)$ & $\bar{\sigma}_{u b i}{ }^{2}\left(\mathrm{~m}^{2}\right)$ & $\sigma_{u r i}{ }^{2}\left(\mathrm{~m}^{2}\right)$ & $\psi_{u i}{ }^{2}\left(\mathrm{~m}^{2}\right)$ & $\sigma_{u{ }^{\prime \prime}}{ }^{2}\left(\mathrm{~m}^{2} / \mathrm{Sec}^{4}\right)$ \\
\hline 5 & $245014 \mathrm{E}-02$ & $.533741 \mathrm{E}-03$ & $.231407 \mathrm{E}-03$ & $.571563 \mathrm{E}-02$ & $.869952 \mathrm{E}-02$ & $.321051 \mathrm{E}-02$ \\
10 & $.179546 \mathrm{E}-01$ & $.391125 \mathrm{E}-02$ & $.169575 \mathrm{E}-02$ & $.418841 \mathrm{E}-01$ & $.637499 \mathrm{E}-01$ & $.235266 \mathrm{E}-01$ \\
15 & $.584374 \mathrm{E}-01$ & $.127301 \mathrm{E}-01$ & $.551921 \mathrm{E}-02$ & $.136322 \mathrm{E}+00$ & $.207489 \mathrm{E}+00$ & $.765727 \mathrm{E}-01$ \\
20 & $.132175 \mathrm{E}+00$ & $.287931 \mathrm{E}-01$ & $.124835 \mathrm{E}-01$ & $.308335 \mathrm{E}+00$ & $.469303 \mathrm{E}+00$ & $.173194 \mathrm{E}+00$ \\
25 & $.242297 \mathrm{E}+00$ & $.527821 \mathrm{E}-01$ & $.228841 \mathrm{E}-01$ & $.565224 \mathrm{E}+00$ & $.860303 \mathrm{E}+00$ & $.317490 \mathrm{E}+00$ \\
30 & $.386227 \mathrm{E}+00$ & $.841360 \mathrm{E}-01$ & $.364778 \mathrm{E}-01$ & $.900981 \mathrm{E}+00$ & $.137134 \mathrm{E}+01$ & $.506087 \mathrm{E}+00$ \\
35 & $.557352 \mathrm{E}+00$ & $.121414 \mathrm{E}+00$ & $.526400 \mathrm{E}-01$ & $.130018 \mathrm{E}+01$ & $.197895 \mathrm{E}+01$ & $.730319 \mathrm{E}+00$ \\
40 & $.745866 \mathrm{E}+00$ & $.162480 \mathrm{E}+00$ & $.704444 \mathrm{E}-01$ & $.173994 \mathrm{E}+01$ & $.264828 \mathrm{E}+01$ & $.977335 \mathrm{E}+00$ \\
45 & $.942683 \mathrm{E}+00$ & $.205355 \mathrm{E}+00$ & $.890331 \mathrm{E}-01$ & $.219907 \mathrm{E}+01$ & $.334711 \mathrm{E}+01$ & $.123523 \mathrm{E}+01$ \\
50 & $.113979 \mathrm{E}+01$ & $.248293 \mathrm{E}+00$ & $.107649 \mathrm{E}+00$ & $.265888 \mathrm{E}+01$ & $.404696 \mathrm{E}+01$ & $.149351 \mathrm{E}+01$ \\
\hline
\end{tabular}

According to Equation (39), Equation (44), Equation (46), Equation (45), Equation (38) and Equation (50), we respectively calculated the mean square value of the static translation displacement response $\mu_{u i}{ }^{2}$, the mean square value of the quasi-static turbulent ground displacement response $\sigma_{u b i}{ }^{2}$, the mean square value of the unreasonable approximate quasi-static turbulent ground displacement response $\bar{\sigma}_{u b i}{ }^{2}$ according to the unreasonable approximate Equation (31), the mean square value of the dynamic turbulent resonant displacement response $\sigma_{u r i}{ }^{2}$, the mean square value of the total displacement response $\psi_{u}{ }_{i}{ }^{2}$ and the mean square value of the acceleration response $\sigma_{u{ }^{\prime \prime}}{ }^{2}$. Considering only the response to the lowest resonant frequency, these mean square values are listed in Table 3 .

Comparing the values of $\sigma_{u b i}{ }^{2}$ and $\bar{\sigma}_{u b i}{ }^{2}$ of Table 2, their relative error is $\left(\sigma_{u b i}{ }^{2}-\bar{\sigma}_{u b i}{ }^{2}\right) / \bar{\sigma}_{u b i}{ }^{2}=130.6 \%$. Even $\left(\sigma_{u b i}-\bar{\sigma}_{u b i}\right) / \bar{\sigma}_{u b i}=51.8 \%$. This fact strongly supports the above-mentioned conclusion that the items corresponding to $\left(I_{r i}{ }^{2}+I_{r j}{ }^{2}\right)$ of Equation (30) can not be neglected as Equation (31) for tall buildings, since the neglecting will cause a $50 \%$ or much higher relative error for $\sigma_{u b i}{ }^{2}$.

\section{Conclusions}

For modern tall buildings built in urban areas with a larger roughness length, the effects of wind-induced random vibrations become more pronounced. The square item of turbulence component $V_{r i}{ }^{2}(t)$ of Equation (9) can not be neglected.

In this paper, a more accurate expression of alongwind load spectrum is proposed. On the basis of this expression form, analysis formula of wind-induced displacement and acceleration response in along-wind direction are developed and programmed.
As the present usual expression of along-wind load neglects the square item of turbulence component, even an approximate form of the accurate expression proposed is more accurate than the present expression. The example strongly supports this conclusion.

\section{References}

[1] A.G. Davenport, "Gust Loading Factors," Journal of the Structural Divasion, 1977, pp. 11-34.

[2] A.G. Davenport, "The Prediction Spectrum of Horizontal Gustiness Near the Ground in High Winds," 1963, pp. 194-211.

[3] C. Dyrbye and S. O. Hansen, "Wind Loads on Structures," John Wiley \& Sons Inc., New York, 1996, pp. 49-106.

[4] C. H. Thorton, L. Joseph, et al., "Optimization of Tall Structures for Wind Loading," Journal of Wind Engineering and Aerodynamics, Vol. 36, 1990, pp. 235-244.

[5] E. Simiu and R. H. Scanlan, "Wind Effcts on Structrures: A Introduction to Wind Engineering," John Wiley \& Sons Inc., New York, 1986.

[6] P. Sachs, "Wind Force in Engineering," Pergamon Press, Oxford, 1978, pp. 12-88.

[7] A. Pupleace, "Probability, Random Variable and Random Process", High Education Press, Beijing, 1983, pp. 18-48.

[8] L. G. Griffis, "Serviceability Limit States Under Wind Load," Engineering Journal of American Institute of Steel Construction, 1993, pp. 23-28.

[9] B. J. Vickery, et al., "The Role of Damping, Mass and Stiffness in The Reduction of Wind Effects on Structures," Journal of Wind Engineering and Industrial Aerodynamics, Vol. 11, 1983, pp. 265-294.

[10] Ad Hoc Committee on Serviceability Research, "Structural Serviceability: A Critical Appraisal and Research Need", Journal of Structural Engineering, Vol. 112, No. 12, 1986, pp. 2646-2664. 
[11] D. Surry and E. M. F. Stopar, "Wind Loading of Large Low Building," Journal of Civil Engineering, Vol. 16, 1989, pp. 526-542.

[12] F. K. Chang, "Human Response to Motions in Tall Building," Journal of Structural Division, Vol. 99, 1973, pp. 1259-1272.

[13] B. Blocken, et al., "Wind, Rain and the Building Envelope:
Studies at the Laboratory of Building Physics," KU Leuven, 2002, pp. 36-66.

[14] L. M. Fitzwater and S. R. Winterstein, "Predicting Design Wind Turbine Loads From Limited Data: Comparing Random Process and Random Peak Models," Journal of Solar Energy Engineering, Vol. 123, No. 4, 2001, pp. 364-371. 